\title{
Avaliação da influência do programa educativo-preventivo odontológico da UBS do Jardim Alvorada (Londrina-PR/Brasil) sobre a educação dos pais das crianças usuárias
}

\author{
Evaluation of the influence of the Jardim Alvorada \\ (Londrina - Pr/Brazil) basic health unit dental \\ educational-preventive program on the oral health education of \\ parents whose children attend the program
}

TAKAHASHI, C.; URSI, W.J.S. Avaliação da Influência do Programa Educativo-Preventivo Odontológico da UBS do Jardim Alvorada (Londrina-PR/Brasil) sobre a Educação dos Pais das Crianças Usuárias. Semina, Londrina, v. 18, ed. especial, p. 90 - 97, fev. 1997.

\begin{abstract}
RESUMO: Com a finalidade de avaliar o conhecimento dos pais de crianças de 06 a 12 anos da Unidade Básica de Saúde (U.B.S.) Jardim Alvorada à respeito de prevenção de cárie e doença periodontal, 85 questionários foram aplicados e seus resultados tabulados $e$ analisados. O trabalho, realizado em 4 etapas, faz um levantamento do $n^{\circ}$ de U.B.S. existentes em Londrina, suas características e posterior escolha de uma U.B.S. para a realização do estudo, bem como a seleção da faixa etária. A partir dos resultados obtidos, verificou-se que existe uma conscientização preventiva por parte dos pais e que a maioria das informações foram obtidas através do programa educativo-preventivo adotado pela U.B.S. Jardim Alvorada.
\end{abstract}

PALAVRAS-CHAVE: Odontologia Preventiva; Educação em Saúde Bucal; Saúde Bucal.

ABSTRACT: Aiming at evaluating the knowledge of parents of 6 to 12 year-old children from the Basic Unit Health (B.U.H.) Jardim Alvorada about the prevention of the decay and

* Autora: Aluna do $5^{\circ}$ ano de Gladunção em Odontologia da Universidade Estadual de Londrina

* Orientador: Prof. Assistente de Materiais Dentários e Dentística da Universidade Estadual de Londrina/Centro de Ciências da Saúde- rua Pernambuco, 540. Fonc (1043) 331-20\%12 - CEP 86120-1770 - Londrina - Paraná. 
periodontological illness, 85 questionnaires were administered and the results were analyzed. The work was done in four stages, and it conducted a survey of the numbers of B.U.H. members existing in Londrina, their characteristics. A B.U.H. was then chosen for the study as well as the selection of the age group. Based on the results it was verified that there is a preventive consciousness of the parents and that most of the information was obtained through the preventive educational program adopted by the B.U.H. Jardim Alvorada.

KEY WORDS: Preventive Dentistry; Parents Education; Oral Health.

\section{INTRODUÇÃO}

O interesse pela prevenção da cárie dental e doença periodontal tomou um impulso muito grande nos últimos anos na classe odontológica e conseqüentemente na conscicntização da população, com um aumento gradativo da socialização dos problemas da saúde bucal.

Apesar dos esforços em se realizar uma odontologia cada vez mais conservadora, a cárie dental e doença periodontal ainda constituem um dos maiores desafios da árca odontológica. PINTO' ${ }^{13}$, num hipotético ranking internacional com base nos 165 países estudados, verificou que o índice C.P.O.D. do Brasil ocuparia a $140^{\circ}$ posição ao lado da Colômbia. Em Londrina/Pr., no entanto, de acordo com os dados da Secretaria Municipal de Saúde, o índice C.P.O.D. em crianças de 6 a 12 anos é de 3.10. Esse valor é muito próximo a meta preconizada pela Organização Mundial da Saúde (O.M.S.) para o ano 2.000 que é de no máximo 3 dentes C.P.O., para essa faixa ctária. Esses dados, sugerem que a cárie dentária $\mathrm{em}$ Londrina, é uma doença controlada, e que os programas de prevenção e orientação de higiene bucal nesta faixa elátia estão sendo satisfatoriamente efícazes.
A cárie dentária é uma doença multifatorial com uma ação simultânea de 3 fatores: hospedeiro, microbiota e substrato. Desta maneira, as estratégias estabelecidas com mais frequência para conseguir a redução e eliminação da cárie são: aumento da resistência do dente; controle do agente microbiano; controle da dieta.

No entanto, estes três campos de atuação se defrontam com problemas muitas vezes intransponíveis por terem que ser empregados em um paciente imaturo e com características próprias que é a criança. São necessários reforços constantes e novas motivações, onde a educação da criança e dos pais devem ser priorizados.

Durante muitos anos, ao se utilizar o termo doença periodontal, o Cirurgião Dentista associava automaticamente este termo à fase adulta do ser humano, porém, nos últimos 20 anos, segundo OLIVEIRA et al. ${ }^{12}$, vários estudos têm demonstrado a suscetibilidade da criança às doenças periodontais, em especial às gengivites, sendo a placa bacteriana reconhecida como fator etiológico de maior importância na docnça periodontal. 
Segundo SANDELL apud MOIMAZ et al ${ }^{10}$, educação para saúde bucal é o processo de provocar uma mudança no indivíduo quanto ao seu comportamento relativo à saúde. Isto implica em um trabalho de conscientização do mesmo quanto a importância, visando torná-lo motivado e receptivo às mudanças.

Baseado nos dados citados, o estudo objetiva avaliar o nível de conhecimento por parte dos pais das crianças de 6 a 12 anos do Posto de Saúde do Jardim Alvorada, localizado na região oeste de Londrina, a respeito de prevenção de cárie e doença periodontal, analisando a eficácia do programa educativo-preventivo deste Centro de Saúde.

Embora conscientes da realidade do baixo índice C.P.O.D. cm Londrina, e particularmente na região oeste que é de 2.83, considerando válidas todas as tentativas de rcpassar à população os conhecimentos necessários para ter-se saúde bucal, o presente trabalho questiona: "Até onde a população (pais) tem a possibilidade de assimilar, de aplicar ou de cumprir aquilo que lhe é ensinado no tocante à prevenção de cárie e doença periodontal ?"

\section{MATERIAIS E MÉTODOS:}

O trabalho foi realizado em 4 etapas:

Etapa 1- Levantamento do $n^{\circ}$ de U.B.S. (Unidades Básicas de Saúde) existentes em Londrina e características do programa educativo-preventivo em Odontologia adotado por estes.

Etapa 2- Escolha da U.B.S. para a realização do trabalho.

Etapa 3- Seleção da faixa etária.

Etạpa 4- Aplicação de questionário aos pais cujos filhos participam do atendimento odontológico da U.B.S.

\section{ETAPA I:}

- O município de Londrina possui uma rede de 49 U.B.S. (Unidades Básicas de Saúde), sendo 15 postos localizados na zona rural e 34 na zona urbana.

- São beneficiados com atendimento odontológico 24 U.B.S. na zona urbana e 06 na zona rural.
- A rede de postos de Saúde em Londrina é dividida em:

\section{Zona urbana:}

-Região Central: 05 U.B.S. sendo $02 \mathrm{com}$ atendimento odontológico

-Região Norte: 08 U.B.S. sendo 07 com atendimento odontológico

-Região Sul: 08 U.B.S. sendo 06 com atendimento odontológico

-Região Leste: 07 U.B.S. sendo 04 com atendimento odontológico

-Região Oeste: 07 U.B.S. sendo 06 com atendimento odontológico

\section{Zona Rural:}

- É composto por 15 U.B.S. sendo 06 com atendimento odontológico.

- O programa edicativo-preventivo que o municipio de Londrina adota para o controle da cárie e doença periodontal é unificado para todos os postos de Saúde. A faixa etária abrangida é de 0 a 14 anos.

- Este prograna é realizado em três níveis:

- Nivel 01: Palestras com todos os pais que irão iniciar tratamento odontológico de seus filhos no Posto. Essas palestras são realizadas por um dos cirurgiões dentistas da U.B.S., visando a conscientização dos pais a respeito das necessidades odontológicas de seus filhos, para entender e aprender como controlá-las, assim como aplicar diariamente as medidas preventivas que deverão usar em casa.

- Nível 02: Conversa individual com os pais ou crianças no decorrer do tratamento realizado pela THD (técnico em higiene dental) ou pelo cirurgiãodentista responsável, direcionando para dificuldades encontradas por cada criança na eliminação dos fatores de risco da cárie ou doença periodontal.

- Nivel 03: Tratamento preventivo ou curativo propriamente dito, onde utilizam intervenções como: técnica de escovação, aplicação tópica de flúor, selante, aplicação do diamino fluoreto de prata, etc. A Odontologia para Bebês preconizada por WALTER et al. ${ }^{18}$ tambén é utilizada. 


\section{ETAPA 2:}

- Partindo do princípio da regionalização, onde cada árca de abrangência das U.B.S. possui uma realidade própria, a pesquisa foi efetuada na U.B.S. do Jardim Alvorada localizada na região oeste de Londrina que atende um total de 22 bairros, com uma população de 18.657 habitantes, pois:

- Esta micro-região possui características homogêneas nas questões sócio-econômica-culturais.

- O atendimento odontológico foi implantado desde a fundação desta U.B.S., em 1.991.

- A Secretaria Municipal da Saúde dispõe de dados do índice C.P.O.D. desde 1.991, podendo verificar que houve um decréscimo deste índice ao longo dos anos.

\section{ETAPA 03:}

- A laixa etária selecionada de 6 a 12 anos, foi escolhida pelos scguintes fatores:

- A Secretaria Municipal de Saúde possui dados epidemiológicos apenas desta faixa etária, pois a implantação da Odontologia para Bebês ocorreu há pouco tempo.

- A Bebê-Clínica da Universidade Estadual de Londrina já possui diversas pesquisas no tocante ao atendimento para bebês mostrando fielmente as características desta faixa etária.

- Segundo LIMA 6 , o período de 6 a 12 anos é a fase mais longa e mais importante por coincidir com o irrompimento de todos os dentes permanentes, onde a destruição dentária provocada pela cárie se apresenta com maior velocidade e intensidade devido a imaturidade das estruturas dentárias. Durante esta fase é necessário o esforço do profíssional e dos pais para a manutenção da saúde bucal da criança.

\section{ETAPA 04:}

- Foi elaborado um questionário direcionado aos pais (Anexo I) abrangendo diversos pontos a respeito de cárie e doença periodontal.

- Participaram do estudo 85 pais de crianças que na época da pesquisa (julho/96) apresentavam a idade de 6 a 12 anos e que não receberam a alta definitiva, correspondendo a $15 \%$ do total de pais de crianças desta faixa etária. A alta definitiva é dada somente quando o paciente atingir a idade de 14 anos e 11 meses. Até esta faixa etária todos recebem atendimento periodicamente.

\section{RESULTADOS EDISCUSSÃO}

Os resultados obtidos estão expressos nas tabelas e gráficos. Do total de pais entrevistados, na pergunta: "Por que procurou tratamento odontológico no Posto de Saúde Jardim Alvorada?", a maioria $(55,30 \%)$ responderam que obtiveram boas informaçoes do atendimento odontológico da U.B.S. Jardim Alvorada. Outras respostas como mora perto $(38,82 \%)$, o dente de seu filho estava doendo $(4,71 \%)$ e já fazia tratamento em outros setores do posto $(12,94 \%)$ também foram citados (tabcla 01). Estes percentuais sugerem que as pessoas que

\begin{tabular}{|c|c|c|}
\hline \multicolumn{3}{|c|}{ Por que procurou tratamento no Posto de Saúde? } \\
\hline Tabela I & Total & $\%$ \\
\hline Mora perto. & 7 & $8,24 \%$ \\
\hline Mora perto. & & \\
\hline Não tem condições de procurar trabalho particular. & 16 & $18,82 \%$ \\
\hline Mora perto. & & \\
\hline Informação de bom atendimento. & 10 & $11,76 \%$ \\
\hline Informação de bom atendimento. & 30 & $35,29 \%$ \\
\hline Informação de bom atendimento. & & \\
\hline Não tem condições de procurar tratamento particular. & 7 & $8,24 \%$ \\
\hline$\overline{\mathrm{O}}$ dente estava doendo. & 4 & $4,71 \%$ \\
\hline Faz tratamento no posto em outros setores. & 11 & $12,94 \%$ \\
\hline Total & 85 & $100,00 \%$ \\
\hline
\end{tabular}

Fonte: UBS do Jardim Alvorada 
participam do atendimento estão fazendo uma divulgação positiva a respeito do tratamento odontológico oferecido pela U.B.S.. No cntanto, se um programa informativo, que vem sido realizado pela equipe da U.B.S. esporadicamente, fosse aplicado efetivamente, os números acima poderiam ser melhorados ainda mais. Este programa, levaria as informações sobre o atendimento educativo-preventivo do setor odontológico até a população, sem esperar que as pessoas recebam informações somente de terceiros, melhorando com isso, as condições de saúde bucal dis crianças desta região.

$\mathrm{Na}$ tabela 02, com a pergunta: "Como se forma a cárie?", 4,71\% dos pais não souberam responder, o restante respondeu satisfatoriamente à pergunta como se observa na tabela, onde as respostas foram associadas basicamente à falta de higiene bucal.

\section{Como se forma a cárie?}

\begin{tabular}{|c|c|c|}
\hline & \multicolumn{2}{|c|}{ Londrina, julho/ 9} \\
\hline Tabela II & Total & $\%$ \\
\hline Não sabe. & 4 & $4,71 \%$ \\
\hline $\begin{array}{l}\text { Se forma através de } \\
\text { restos de alimentos na boca. }\end{array}$ & 21 & $24,71 \%$ \\
\hline $\begin{array}{l}\text { A placa bacteriana produz } \\
\text { ácidos que vai deleriorando o } \\
\text { dente e forma a cárie. }\end{array}$ & 25 & $29,41 \%$ \\
\hline Falta de escovação. & 20 & $23,53 \%$ \\
\hline $\begin{array}{l}\text { O doce/açúcar vai formar a } \\
\text { cárie se não escovar os dentes. }\end{array}$ & 15 & $17,65 \%$ \\
\hline Total & 85 & $100,00 \%$ \\
\hline
\end{tabular}

Fonte: UBS do Jardim Alvorada

MIAIRA et al. apud OLIVEIRA 12, baseando-se nas observações de vários autores, afirmaram que atualmente a placa bacteriana é o fator etiológico mais importante da doença periodontal e esta, em conjunto com a cárie dental, são responsáveis por $97 \%$ das exodontias. Na tabela $03,56,47 \%$ dos pais não souberam responder a pergunta: "Como se forma a doença da gengiva?", $16,47 \%$ responderam que se forma através do acúmulo de alimentos entre o dente/gengiva e $12,94 \%$ através da placa bacteriana. Estes dados demonstram que faltam informações a respeito de doença periodontal e que maior ênfase poderia ser dada sobre este assunto, mostrando a gravidade e o modo de se prevenir da doença periodontal, pois SARIAN et al. apud OLIVEIRA ${ }^{12}$, baseando-se em vários estudos, afirmaram que a criança tem susceptibilidade às doenças periodontais em especial às gengivites. Eles afirmaram que não existe melhor recurso de prevenção da doença periodontal que os meios mecânicos de higiene bucal (escova, fio dental) e que são os pais, os responsáveis iniciais pela execução dessa prevenção.

\section{Como se forma a doença da gengiva?}

\begin{tabular}{lcc}
\hline \multicolumn{1}{c}{ Tabela III } & Total & $\%$ \\
\hline $\begin{array}{l}\text { Não sabe. } \\
\begin{array}{l}\text { Através do acúmulo de } \\
\text { alimentos entre o } \\
\text { dente e a gengiva. }\end{array}\end{array}$ & 48 & $56,47 \%$ \\
\hline $\begin{array}{l}\text { Através da placa bacteriana. } \\
\text { Através da má escovação. }\end{array}$ & 11 & $16,47 \%$ \\
\hline $\begin{array}{l}\text { A raiz do dente infectada } \\
\text { forma a doença da gengiva. }\end{array}$ & 8 & $9,41 \%$ \\
\hline \begin{tabular}{l} 
Total \\
\hline Londrina, julho/96
\end{tabular} & $\mathbf{8 5}$ & $\mathbf{1 0 0 , 0 0 \%}$ \\
\hline
\end{tabular}

Os dados apresentados na figura $n^{\circ} 01$ e $n^{\circ} 02$, serviram para estabelecer quais os meios de prevenção de cárie e doença periodontal de que os pais têm conhecimento e se as orientações estão sendo seguidas corretamente pelos seus filhos. Na questão: "Como seu filho deve se prevenir da cárie e doença da gengiva?", a totalidade $(100 \%)$ dos pais responderam através da escovação, outras como: uso do fio dental, flúor, dieta alimentar, ir ao dentista regularmente foram citados $\mathrm{em}$ menor proporção. Quanto às orientações seguidas pelos seus filhos (figura 02), a escovação após as refeições $(70,58 \%)$ e a escovação antes de dormir $(81,17 \%)$ também foram os ítens mais citados. Estes dados demonstram que as informações sobre os benefícios da escovação estão atingindo a população em massa, sendo necessária maior ênfase aos outros fatores de prevenção. O controle mecânico da placa tem na escovação e no fío dental os principais métodos por se tratarem de técnicas que podem ser executadas freqüentemente e pelo próprio paciente. No entanto, o controle da placa pelo uso da escovação e fio dental, depara com um problema muito 
sério que são as limitações do próprio paciente pela sua peculiar característica e pelo seu desenvolvimento motor que dificulta o aprendizado e a prática das técnicas, necessitando, com isso, de uma interação entre os vários meios de prevenção.

Observa-se na figura 02 que $81 \%$ dos pais obtiveram as informações através da U.B.S.. É interessante observar que $12 \%$ responderam que a Bebê Clínica da UEL foi a fonte inicial das informações, sugerindo que uma maior integração Serviços-Universidade-Comunidade seja primordial para a continuidade de programas de educação da saúde bucal.

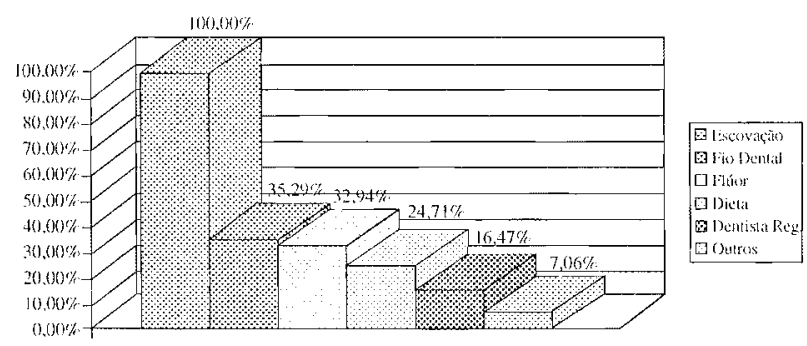

FIGURA 01

Como seu filho deve se prevenir da cárie e da doença da gengiva?

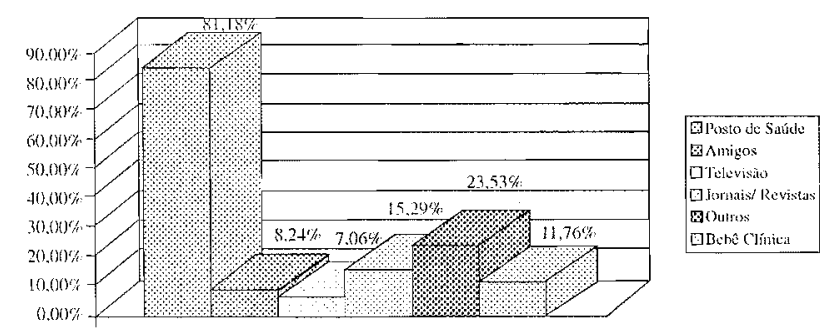

FIGURA 02

Onde você obteve essas informações?
Os dados obtidos através desta avaliação observada no figura 03 , onde $98 \%$ responderam estar satisfeitos com o tratamento odontológico da U.B.S., demonstram estar ocorrendo uma receptividade positiva dos pais quanto às orientações passadas sobre prevenção de cárie e doença periodontal, necessitando de certos aprimoramentos onde o processo educativo dos pais e crianças seja primordial para uma mudança de comportamento do indivíduo nos valores relativos à saúde.

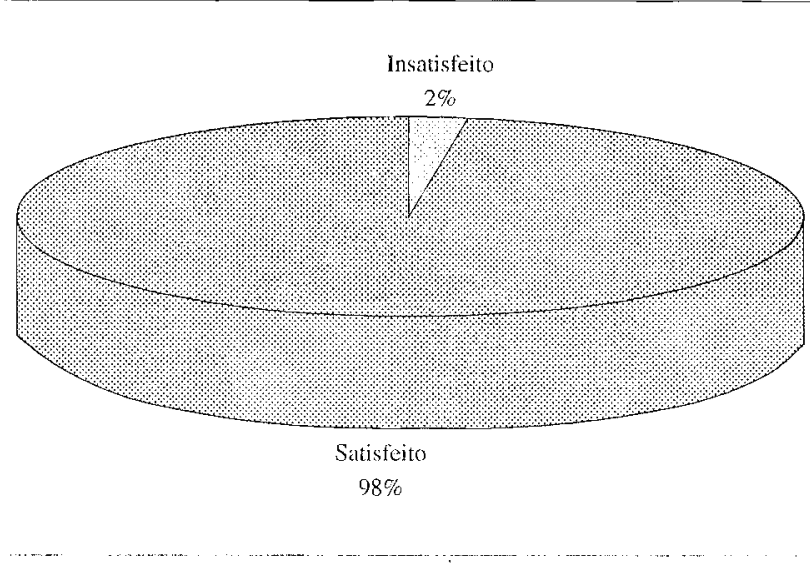

FIGURA 03

Você está satisfeito com o tratamento odontológico do posto de saúde?

\section{CONCLUSÃO}

A partir da análise dos resultados, pode-se concluir que:

- A maioria dos pais estão satisfeitos com o tratamento odontológico da U.B.S. do Jardim Alvorada e com sua equipe de trabalho.

- A população estudada possui conhecimento a respeito da etiologia e prevenção da cárie. São necessários maiores informações aos pais sobre doença periodontal. Alguns aprimoramentos no programa educativo-preventivo adotado pela U.B.S., levaria a uma melhor disseminação destas informações e conseqüentemente a um trabalho preventivo mais eficaz. No entanto, a U.B.S. Jardim Alvorada vem conseguindo obter um baixo índice C.P.O.D. nas crianças de 6 a 12 anos. 
- O trabalho do setor odontológico adotado pela Secretaria Municipal de Saúde de Londrina, é unificado para lodas as U.B.S., diferenciando-se em alguns aspectos por tratar-se de equipes de trabalhos diferentes, onde o modo de conduzir o trabalho será diferente para cada U.B.S.

- O reconhecimento da realidade de cada área de abrangência das U.B.S., buscando as verdadeiras características da população, é necessário para que ocorra um efetivo trabalho educativo-preventivo, suprindo as necessidades e deficiências de cada micro-região.

- Uma maior integração Serviço-UniversidadeComunidade torna-se necessária para que todos sejam beneficiados com esta troca de experiência, e a academia compreenda a verdadeira realidade da população, integrando-se com os Serviços e obtendo uma melhoria na qualidade da saúde bucal da comunidade.

\section{REFERÊNCIAS BIBLIOGRÁFICAS}

01- ALMEIDA, R.T.L.S. ; LIMA, E.G. et al. Determinação do índice de placa dental em escolares da rede municipal de ensino de Ribeirão Preto-São Paulo. $R$ e $v i$ is $i$ a Paulista de Odontologia, São Paulo, v.XVIII, n.06, p.11-14, nov.-dez. 1991.

02- CHAVES, M.M.. Odontologia Social. 3.ed. São Paulo: Artes Médicas, 1986. 282 p.

03- CONFERÊNCIA MUNICIPAL DE SAÚDE, Londrina, 2223 set. - 1995. A situação do SUS, atendimento e soluçôs. 1995.

04- GAVAZZI, J.C. ; HOFLING J.F. et al. Previsores do Incremento dc Cáric em crianças Escolares Brasileiras. Revista da Associação Paulista de Cirurgiões Dentistas, São Paulo, v.49, n.01, p.40-45

05- GIL, I.A. ; MORAES, A.B.A. Treinamento de Escovação Dentária em crianças. Revista Gaúcha de Odontologia, Belo Horizonte, v.40, n.06, p.401-404, nov.-dez. 1992.
006- LIMA, J.E.O. Um plano de Prevenção para consultório Odontopediátrico. Revista Gaúcha de Odontologia, Belo Horizonte, v.40, n.06, p.395-399, nov.-dez. 1992

7- LONDRINA, Prefeitura Municipal. Secretaria da Saúde. Departamento de Serviços de Saúde. Relatório da Oficina de Territorialização e Estimativa Rápida Participativa do Posto de Saúde do Jardim Alvorada, 1994.

08- MEDEIROS,U.V. Saúde Bucal - Comunidade. Percepção da necessidade de saúde bucal pela comunidade. Revista da Associação Paulista de Cirurgiões Dentistas, São Paulo, v.43. n.03. p.120-124, mai.-jun. 1989.

09- MESTRINO, H.D. ; CARVALHO, y.C. et al. Desempenho Clínico das Escovas Infantis Produzidas no Brasil. Revista Gaúcha de Odontologia, Belo Horizonte, v.42, n.05, p.254-258, set.-out. 1994.

10- MOIMAZ, S.A.S. ; SALIBA, N.A. et al. Educação para Saúde Bucal e Prevenção. Revista Gaúcha de Odontologia, Belo Horizonte, v.42, n.02, p.71-74, mar. abr. 1994.

11 - MILANEZI, L.A. ; NAGATA, M.J.H. el al. Uso dos Agentes de Limpeza Dentária. Revista Gaúcha de Odontologia, Belo Horizonte, v. 42 , n.02, p.101-104, mar.-abr. 1994.

12- OLIVEIRA, G.C.R. ; GAUCH, A.L. et al. Higiene Bucal Orientada. Revista Gaúcha de Odonto logia, Belo Horizonte, v.40, n.06, p.388 39?, nov.-dez. 1992

13- PINTO, V.G. Índice de Cárie no Brasil e no Mundo. Revista Gaúcha de Odontologia, Belo Horizonte, v.44, n.01, p.08-12, jan.fev. 1996

14- PINTO, V.G. Revisão sobre o uso e segurança do Fínor. Revista Gaúcha de Odontologia, Belo Horizontc, v.41. n.05, p.263-265, set.-out. 1993

15- PINTO, V.G. Saúde Bucal - Panorama Internacional. Brasília: Ministério da Saúde, 1990. 257 p.

16- PINTO, V.G. Odontologia Social e Preventiva. 3.ed. São Paulo: Santos Livraria, 1992.415 p.

17- TODESCAN, J.H. ; SIMA, F.T. Campanhas de Prevenção e Orientação para com a Higiene Bucal. Revista da Associação Paulista de Cirurgiões Dentistas, São Paulo, v.45, n.04, p.537-539, jul.-ago. 1991.

18- WALTER, L.R.F. ; FERELLE, A. et al. Odontologia para o Bebê. São Paulo: Artes Médicas, 1996. 246 p. 


\section{ANEXO I \\ QUESTIONÁRIO}

01) Qual a idade do seu filho ?
( ) 06 anos;
( ) 08 anos;
( ) 10 anos;
( ) 12 anos;
( ) 07 anos;
( ) 09 anos;
( ) 11 anos.

02) Por que procurou tratamento odontológico no Posto de Saúde ?

03) Como se forma a Cárie ?

04) Como se forma a Doença da Gengiva?

05) Como seu filho deve se prevenir da Cárie e Doenças da Gengiva?

06) Onde você obteve essas informações?
( ) Posto de Saúde
( ) Televisão
( ) Jornais e Revistas
( ) Amigos
( ) Rádio
( ) Outros:

07) Todas as orientações que lhe foram passadas na Clínica Odontológica do Posto de Saúde está sendo realizada pelo seu filho?
( ) $\operatorname{Sim}$
( ) Não

08) Se a resposta for Não, quais são as orientações que estão sendo seguidas ?

09) Como você (pais) está colaborando para a prevenção da Cárie e Doença da Gengiva no seu filho ?

10) Quais os tratamentos que a Clínica Odontológica do Posto de Saúde está realizando no seu filho para prevenir a Cárie e Doença da Gengiva ?

( ) Limpeza dos Dentes

( ) Ensinando a Escovação dos Dentes

( ) Selante

( ) Diamino Fluoreto de Prata (Flúor que deixa o dente escurecido)

( ) Aplicação de Flúor

( ) Outros:

11) Você está satisfcito com o tratamento Odontológico do Posto de Saúde ?
( ) $\operatorname{Sim}$
( ) Não

Semina, v. 18, ed. especial, p. $90-97$, fev. 1997 